\title{
Recent Developments in Blast Furnace Technology
}

\author{
Piyush Anghan*, Akshay Bhadiyadra**, Rahul Kathiriya*** \\ *(Department of Metallurgical and Materials Engineering, The M. S. University of Baroda, Vadodara, India \\ Email: piyushanghan99044@gmail.com) \\ ** (Department of Metallurgical and Materials Engineering, The M. S. University of Baroda, Vadodara, India \\ Email: akshaybhadiyadra3970@gmail.com) \\ *** (Department of Civil Engineering, Neotech Institute of Technology, Vadodara, India \\ Email : rahulkathiriya35@gmail.com)
}

\begin{abstract}
A huge production of steel throughout the world requires sufficiently large production of hot metal. Inspite of alternative methods of iron making $94.1 \mathrm{wt} \%$ iron is still being produced by blast furnace route only. Blast furnace technology has been developed step by step from primitive blast furnace to modern blast furnace from 14th century till date. During last five decades several important technological changes have taken place to make blast furnace technology eco-friendly, energy efficient and cost effective, increasing its productivity significantly .A characteristic feature of the development of blast furnace technology during last two decades is the increase in its overall productivity to an average of approx. $2.5 \mathrm{t} / \mathrm{m} 3 /$ day and reduce the coke consumption significantly. The objective of the paper is to discuss major technological developments in the blast furnace technology namely higher oxygen enrichment from about 21 to 30\%, lower hot blast temperature from about 1200 to $800^{\circ} \mathrm{C}$, pulverized coal injections within the tuyeres and raceway of the blast furnace upto $250 \mathrm{~kg} / \mathrm{THM}$, better burden distribution and the recent technology for the top charging devices and the technology improvement to create high top pressure like Gimble top device. Further possible improvements in blast furnace technology are lower temperature blast enriched with high oxygen, probability of eliminating hot blast stoves and significant use of top gas.
\end{abstract}

Keywords: blast temperature, burden distribution, coke consumption, hot blast stove, Hot metal, productivity.

\section{INTRODUCTION}

In the blast furnace, there are number of probable development areas which are briefly discussed below:

Such as replacement of coke with auxiliary fuels like pulverized coal, coal tar, natural gas, etc. By adding this we can get high replacement ratio and also this paper gives core details of evaluation of introducing cheaper fuel through the tuyeres. And there are also probability of modern development towards eliminating hot blast stoves with using oxygen enriched and less heated hot blast. A large amount of energy is required in the production of steel where the preheating of blast in the hot blast stoves for iron-making is one of the most energyintensive processes. To improve the energy efficiency it is necessary to investigate how to improve the hot blast stove operation. Hot blast stoves work as counter-current regenerative heat exchangers, and they are often heated up by the process gases generated from the steelworks, such as $\mathrm{BF}$ gas and coke oven gas (COG). In the top charging device of blast furnace, new technology has been updated with various features Rotary Eccentric Burden Distributor (REBD) is introduced in many furnaces top to eliminate the material preferential segregation problem. Burden distribution inside the furnace was also controlled somehow by introducing moveable throat armor in many furnaces in India. For example, Gimble top device can uniformly distribute the charge material and also it can help into creating high top pressure.

\section{MAJOR AREAS OF BREAKTHROUGH IN B/F:}

The major developments that have taken place since 1950s and also the predictions for further changes in $\mathrm{B} / \mathrm{F}$ technology are as given : large size range lump iron ore and its fines to the use of prepared burden(processes like sintering, pelletizing),better quality coke in a closer size ranges, larger furnace volume, higher blast furnace temperature ,advanced in theory of iron making ,better understanding of internal state of the furnace, computer aided process control, online simulation ,oxygen enrichment of the blast, high top pressure ,better burden distribution and control ,injection of auxiliary fuels through the tuyeres, by critical hot blast temperature. 


\section{INJECTION OF THE AUXILIARY FUEL AND RECENT TECHNOLOGY OF TUYERES \& RACEWAY:}

The injection of hydrocarbon through the tuyeres in the form of oil and natural gas had been practiced to various extents in order to minimize the consumption of coke \& increase the productivity of blast furnace. The oil scarcity and crisis starting in 1970s Made such injection unattractive and tuyeres injection now come back in the form of injection of pulverized non metallurgical coal. Process parameter such as aflame temperature and pressure differential over the burden, tuyer injection also benefit the blast furnace process enormously because it contain high volatile matter normally also exhibits superior combustibility owing the fact that the char of high volatile matter coal is more porous, and hence more reactive, very high VM levels lower carbon available, and hence there is a max. value for PCI coal. Ash in coal is undesirable since it increase the slag volume and affects both fuel efficiency and productivity. High ash in PCI coal also tends to increase silicon content in hot metal.

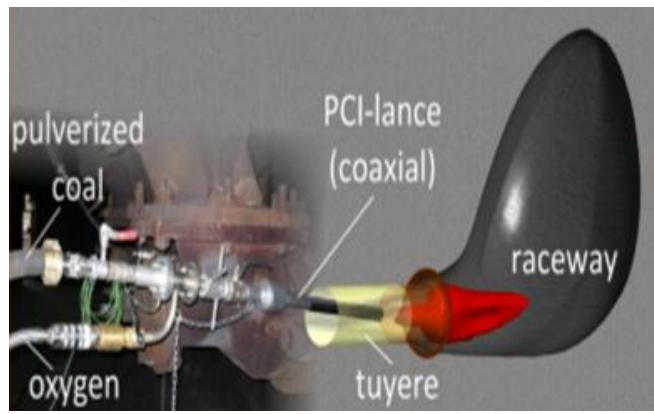

The endothermic decomposition of the injected coal lowers the shaft temperature. However, since this is not always sufficient, simultaneously oxygen enrichment becomes a must. For such a situation several models have been proposed for calculating the RAFT temperature, the formula used by nippone steel, JAPAN, is $\mathrm{O}_{2}$

$T_{f}=1524.0+60 R_{O 2}+0.84 T_{b}-2.7 R_{\text {coal }}-6.3 M_{b}$

Where,

$\mathrm{T}_{\mathrm{f}}=\mathrm{RAFT}$ temperature, ${ }^{0} \mathrm{C}$

$\mathrm{R}_{\mathrm{o} 2}=$ oxygen enrichment rate, vol\%

$\mathrm{T}_{2}=$ blast temperature, ${ }^{0} \mathrm{C}$

$\mathrm{R}_{\text {coal }}=$ coal injection rate, $\mathrm{kg} / \mathrm{thm}$

$\mathrm{M}_{\mathrm{b}}=$ moisture content in blast, $\mathrm{gN} / \mathrm{m}^{3}$

\section{METHODS OF EVALUATION:}

If PCI technology is used, it is very important to evaluate its technological and economical success. The most reliable PCI evaluations are of course operational results. But operational PCI results can only be determined after installation of the corresponding PCI technology at the blast furnace. Furthermore it is very difficult or in some case impossible to determine reliable measured values for example inside the raceway. For the decision which PCI technology or which possible PCI optimization strategy should be used it is necessary to forecast the performance of the corresponding PCI technology and its effect on the blast furnace process. That's the reason why Küttner developed its own gas flow and PCI process model of the tuyer and the raceway of the blast furnace.

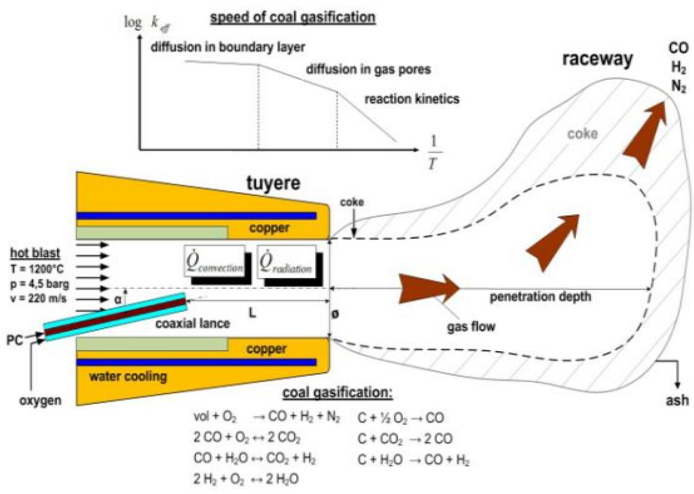

Fig: kuttner's gas flow and PCI process model

Using PCI at the blast furnace it is very important that as much pulverized coal as possible is converted as fast as possible within the tuyere and the raceway. Thereby, the speed of coal gasification depends on the temperature, and is determined by either the chemical kinetics or the diffusion in coal particle pores, or the diffusion through the particle encircling interface. The reaction space in the tuyere is known explicitly, whereas the shape of the reaction space in the raceway can be traced back on endoscopic researches made by Greuel. The penetration depth of the raceway is calculated in dependence of the kinetic energy of the hot blast according to the semi-empirical model of Peters. The three dimensional gas flow is described by steadystate Reynolds-averaged conservation equations for mass, substance, momentum, and energy. The coal particles are modeled as a disperse phase according to the Lagrange-method. That model calculates injected coal particle characteristics on the basis of a balance of forces along discrete trajectory at which particle-particle interactions are disregarded. The heating of the disperse phase is modeled by radiation and convective flow of heat. For the description of the burnout of injected coal particles a standard coal combustion model is used, in which the Boudouard reaction and the heterogeneous water-gas reaction are added to the heterogeneous surface reactions, like the partial oxidation of carbon. The transport of the different gases within the gaseous phase, and their reactions among each other, is described by the finite rate/Eddy-dissipation-model, in which the 
speed of reaction is either limited by the Arrheniusrate depend on temperature, or by turbulent mixing of the reacting agents. The complexity of that physical model is down to simultaneously solving the formulation of the three-dimensional two-phase flow superimposed by the coal gasification reactions, and considering heat radiation and convection. To solve the resulting complex system of equations a computational fluid dynamic (CFD) tool is used.

Figure illustrates the operational results of the increased PCI and decreased coke rate related to blast furnace based on the average consumption in 2015:

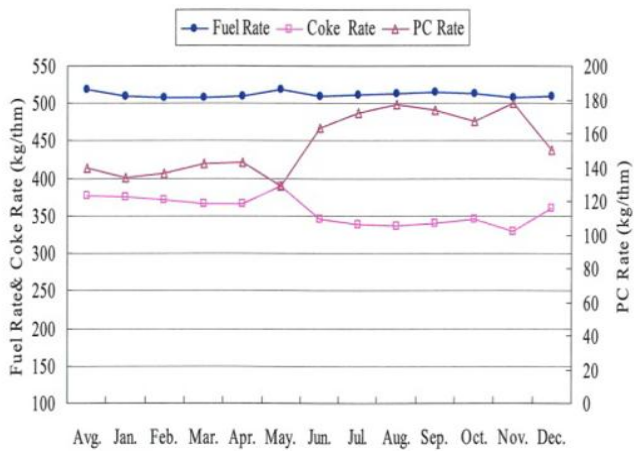

Fig : PCI, coke and total fuel rate of blast furnace in 2015

\section{DEVELOPMENTS OF HOT BLAST STOVES AND PREDICTION FOR ITS FUTURE}

Blast Furnace produced $1500-1700 \mathrm{Nm} 3$ of gas per ton of liquid metal. Calorific value of this gas is as high as $3500-4000 \mathrm{~kJ} / \mathrm{Nm} 3$. It means one third of total energy input of the blast furnace is removed by off gas .In early age cold air was blown into furnace resulting high reduction rate in the blast furnace. Stove size is clearly dependent upon the hot blast volume required for the blast furnace. In order to maintain acceptable levels of flue gas velocity.

Hot blast stoves are required to provide hot blast air to the blast furnace. These regenerative heat exchangers have been first used in the 19th century: Eduard Alfred Cowper submitted a patent application in 1857 for a regenerative brick type heater for heating the blast, a prototype of the hot blast stove. Since then, the hot blast stove system has been subject to many improvements and has evolved to a hot blast system characterized by high efficiency and long campaign life.

There are also implements of the recent developed design of the hot blast stoves (kalugin):

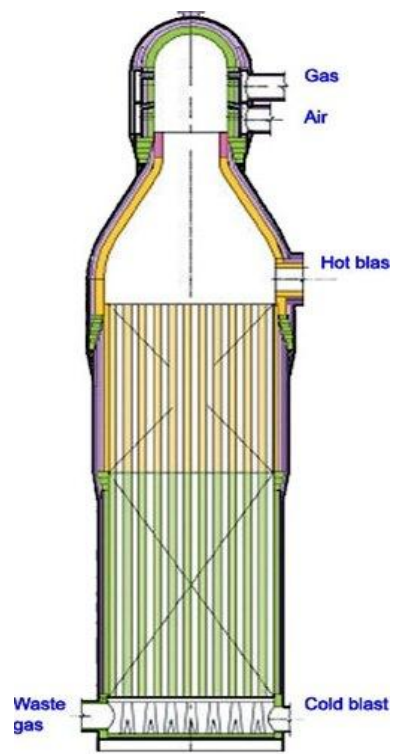

Fig: Section of kalugin stoves

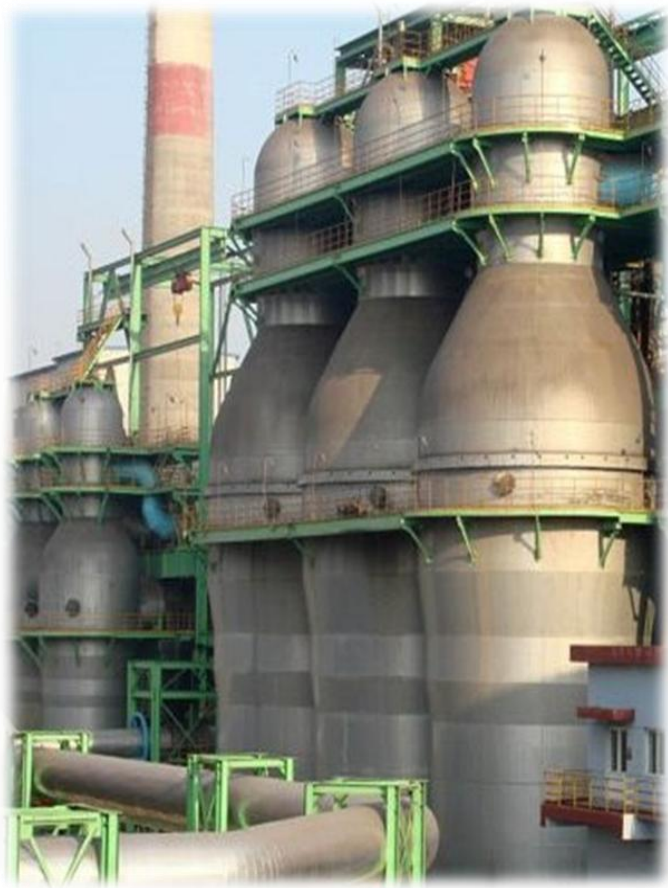

Fig: In industries kalugin stoves

A variety of designs have been developed by Hoogovens, Krupp Koppers, Didier, Martin \& Pagenstecher and more recently Kalugin (fig). These designs include internal, external and dome combustion hot blast stoves. Each design has distinct characteristics, but also resembles many similarities. For example, each hot blast stove includes a ceramic burner, checker support, checkers and these days external waste gas heat recovery systems are also often utilized.

The typical efficiency of a new hot blast stove is $75-80 \%$ : the implementation of a waste gas heat recovery system can increase the system 
efficiency up to $85 \%$. A typical hot blast stove and system efficiency illustration and evaluation of the contribution of an external heat exchanger system is illustrated in below fig:

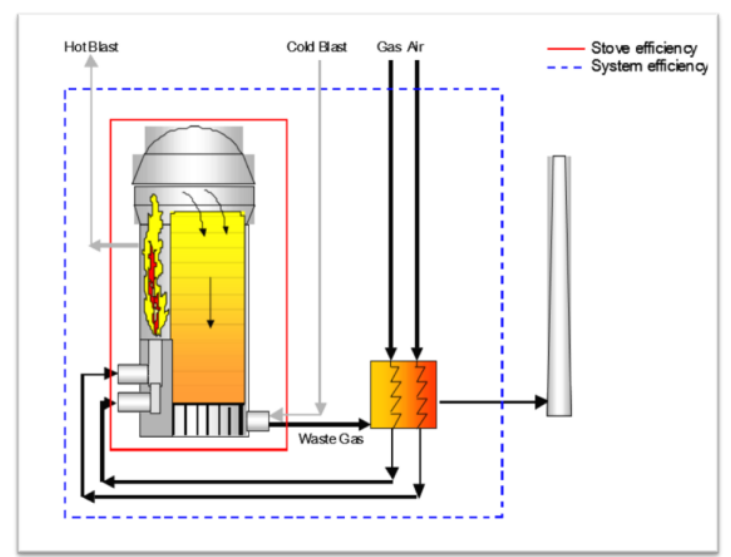

Fig: Stove and system efficiency

The future of hot blast stoves is determined by historical and current developments and improvements, which are mainly driven by suppliers in order to secure a competitive edge and unique selling points. Industrial trends which are widely observed include the pursuit of lower $\mathrm{CO} \& \mathrm{SO}_{\mathrm{x}}$ emissions, elimination of enrichment gas, implementation of waste gas heat recovery and increased efficiency, which can be accomplished by changes to the checker and checker support system. These changes also reduce the hot blast stove dimensions and associated costs.

To-date, campaign life of over 30 years is common practice and inter-crystalline stress corrosion is prevented by innovative coatings and external insulation or double-shell practice. Hitherto, all designs converge towards most efficient systems, whereas construction schedule are often critical in selecting a specific technology.

Significant changes are expected as a result of innovative iron making process technologies. These innovations target reduced $\mathrm{CO} 2$ emissions and increased energy efficiencies as energy and environment will change the nature of our industry comparable to changes as a result of health $\&$ safety.

These innovative iron making technologies permit lower hot blast temperatures and several technologies eliminate the need for hot blast stoves. Hitherto, it is concluded that future hot blast stoves dimensions will be reduced and may eventually disappear. The future of stoves is yet uncertain and schematically illustrated in Figure:

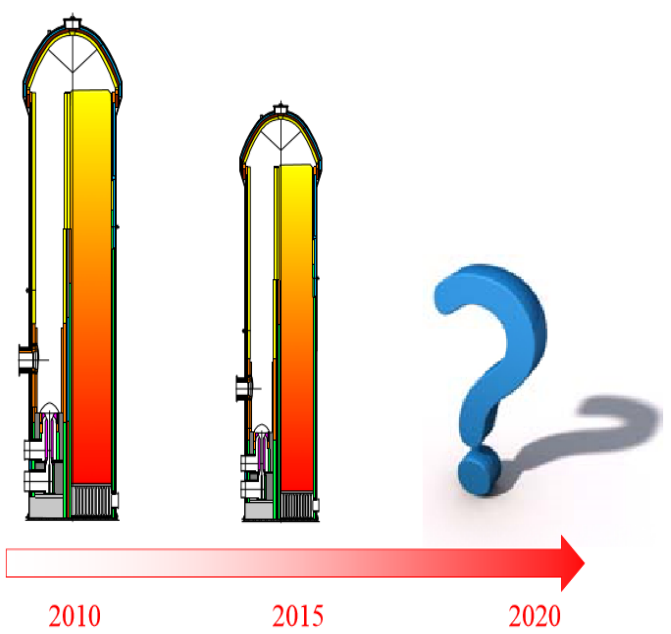

Conclusion section must be included and should indicate clearly the advantages, limitations, and possible applications of the paper. Although a conclusion may review the main points of the paper, do not replicate the abstract as the conclusion. A conclusion might elaborate on the importance of the work or suggest applications and extensions.

\section{OXYGEN ENRICHMENT IN HOT BLAST:}

Recent years energy intensive processes have shown their great interests on applying oxygen-enriched/oxy-fuel combustion technology to industrial furnaces. Compared to air fuel combustion, oxygen enrichment requires less fuel for reheating in commercial installations due to the reduction in heat losses to the fuel gas associated with reduction or the Swedish and Finnish National Committees of the International Flame Research Foundation - IFRF elimination of nitrogen from the process gas stream. The theory of oxygen-enriched combustion can be found in. There are also some other advantages for using oxygen enrichment combustion technologies, such as lower $\mathrm{NO}_{\mathrm{x}}$ emissions, higher productivity, improved temperature stability and heat transfer.

The conventional oxygen enrichment for the hot stove is to inject oxygen via the combustion air. The economic analysis on the hot stove oxygen enriched combustion can be found. The oxygen enriched can be heated up together with the combustion air if the heat exchanger is installed. A new concept is to add oxygen into flue gas which recirculates back to the hot stove after combustion to replace the combustion air. By doing so, parts of sensible heat in the flue gas can be recovered. In addition, the heat exchanger can also be chosen for this new concept. The conventional oxygen enrichment combustion often leads to a high flame 
temperature or peak temperature. However, this could be better under the flue gas recirculation oxygen-enriched combustion. As shown in Figure, the patterns of flame temperature distributions for the flue gas recirculation oxygen enrichment combustion become more flat due to the dilute effect of the recirculate flue gas.

Oxygen enrichment increases the productivity as shown in below graph:

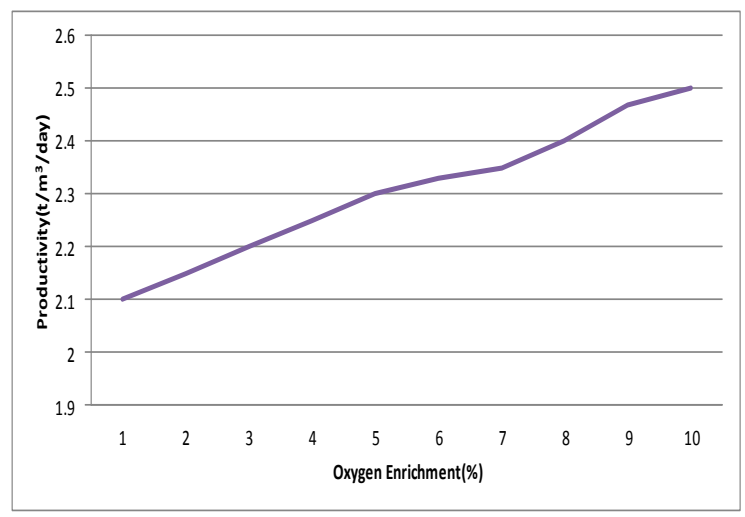

\section{BURDEN DISTRIBUTION}

There are various changes and the development takes placed in the charging devices with the time and there are various features are also come in the field of the top charging devices. Burden distribution plays an important role as far as stable and efficient furnace operation. Proper burden distribution plays a vital role for furnace efficiency and control. In 1880, double bell charging system was introduced with vertical hoist, which was being replaced by skip hoist in 1883. But for uniform burden distribution point of view, it became failure, so that latter on in 1890; Rotary Eccentric Burden Distributor (REBD) is introduced in many furnaces top to eliminate the material preferential segregation problem. Burden distribution inside the furnace was also controlled somehow by introducing moveable throat armor in many furnaces in India. But in 1970 Paul Worth (PW) developed bell less top charging system and recently developed design is a Gimble top device the main feature is we can feed the charge in furnace based on requirement and also at different angle we can rotate and tilt the distributor chute.

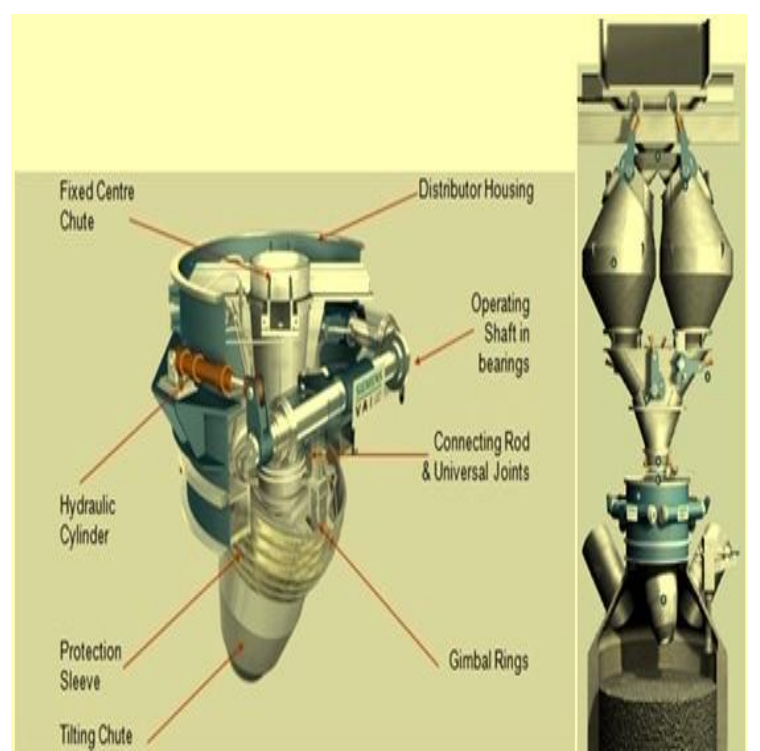

Fig: Gimble top charging device (recently developed)

\section{CONCLUSION}

The presented work illustrates that the application of these technologies have contributed to the improvement in productivity and operational stability of large-scale blast furnaces and to the elongation of blast furnace life. Different strategies and methods have been suggested from the model to achieve the minimum energy consumption. An analysis of oxygen enrichment into hot blast will affect the total energy system has been carried out by means of an optimization model. Oxygen enrichment into hot blast can lead to a lower coke or fuel injection rate in $\mathrm{BF}$ if the blast temperature is allowed to increase. High calorific value coke oven gas can also be saved by use of oxygen enrichment and also burden distribution, pulverized coal injection, technological implementation in hot blast stoves also playing vital role in the improvement in quality, cost, process efficiency and productivity.

\section{REFERENCES}

[1] Model development of a blast furnace stove, The $7^{\text {th }}$ International Conference on Applied Energy - ICAE2015

[2] THE FUTURE OF HOT BLAST STOVES, R. van Laar and J. Barel, Danieli Corus BV

[3] Technological Changes in Blast Furnace Iron Making India since Last Few Decades, A. K. Mandal, O. P. Sinha, IJSR, Volume 2 Issue 12, December 2013

[4] Application of oxygen enrichment in hot stoves and its potential influences on the energy system at an integrated steel plant, WORLD RENEWABLE ENERGY CONGRESS-2011. 
[5] Optimization strategies for pulverized coal injection into the blast furnace, R. Schott, Küttner GmbH \& Co. KG, Germany

[6] Modern Iron Making Technology, R. H. Tupkary and V. H. Tupkary, book.

[7] Iron Making and Steel Making, Amit Chettarji, book.

[8] www.worldsteel.org 